CASA, Vol.9 n.1, julho de 2011

C

Cadernos de Semiótica Aplicada

Vol. 9.n.1, julho de 2011

Publicação SEMESTRAL

ISSN: $1679-3404$

\title{
CONSTRUÇÃO DISCURSIVA DO ADULTO POR JOVENS FRANCESAS: PERSPECTIVA DINÂMICA
}

\author{
DISCURSIVE CONSTRUCTION OF "BEING AN ADULT" BY FRENCH YOUNG \\ WOMEN: \\ A DYNAMIC PERSPECTIVE
}

\author{
Elizabeth Harkot-de-la-Taille \\ USP - Universidade de São Paulo
}

Françoise Bariaud

Université de Rennes 2- Laboratório "Dynamiques de la construction du Soi"

\begin{abstract}
RESUMO: O que é ser adulto? Eis uma questão pouco debatida, na academia. Essa e outras perguntas afins foram submetidas a três grupos etários, de cerca de 16, 20 e 25 anos, de jovens francesas da cidade de Rennes, em entrevistas compreensivas. Após uma triagem por qualidade sonora e profundidade de abordagem do tema, restou um corpus de quatorze entrevistas, gerando um total aproximado de 250 minutos de documentos sonoros. Esses documentos foram analisados pela perspectiva da semiótica discursiva, com o fim de identificar a construção discursiva do adulto em cada uma das três faixas etárias e entre elas. Pôde-se constatar que a ideia de o que é ser adulto não é a mesma aos 16, 20 e 25 anos. De bastante idealizado aos 16 anos, o adulto vai-se humanizando paulatinamente. Mesmo mais humanizado, o adulto permanece muito próximo à imagem tradicional do homem provedor. De quatorze entrevistadas, treze afirmam não serem e não quererem se tornar adultas. Atribuímos essa relutância a uma mudança de perspectiva: antes, o jovem era pensado em relação ao adulto, preparava-se para sê-lo; hoje, o adulto é pensado em relação ao jovem, como aquele que perde uma série de prerrogativas.
\end{abstract}

PALAVRAS-CHAVE: Construção discursiva; Jovem; Adulto; Semiótica discursiva; Entrevistas compreensivas.

ABSTRACT: What is being an adult? There is not much discussion about this issue in the academy. This and other related questions were submitted to French young women from Rennes, in comprehensive interviews. After screening the interviews for sound quality and depth of approach to the topic, we were left with a corpus of fourteen samples, generating approximately 250 minutes of recorded documents. These documents were analyzed from the perspective of discourse semiotics, in order to detect the discursive construction of being an adult, in each of the age ranges and between them. It was shown that the idea of what being an adult is does not remain the same at 16, 20 and 25 years of age. From a highly idealized representation, for the group at age 16, the adult is gradually humanized. However, it is still the traditional image of the male breadwinner that reigns. Thirteen out of the fourteen interviewed young women say they are not and do not want to 
become adults. We attribute this reluctance to a change in perspective: in the past, the young were thought of in relation to adults, preparing to be so; today, it is the adult who is thought of in relation to the young, as the one losing a number of privileges.

KEYWORDS: Discursive construction; Young adult; Adult; Discourse semiotics; Comprehensive interviews.

\section{Introdução}

Setecentos e quarenta e um. Esse foi o número de registros acessados no Dédalus ${ }^{1}$ para se chegar a três trabalhos sobre representações do adulto por jovens. Combinando-se palavras-chave tais como adolescente, adulto, jovem, identidade, imagem, representação, adolescência, juventude e suas traduções em inglês, quatro títulos pareciam evocar representações que os jovens fazem do adulto. No contato com os textos completos, todavia, um se eliminou: investigava a representação do adulto no sentido de "a representação que o adulto faz de algo ou alguém", e não "a representação que dele fazem". Dos três restantes, um é de nossa autoria. Ficamos com dois: Pimenta (2008). "“Ser Jovem' e 'Ser Adulto': identidades, representações e trajetórias"; e Imanishi (2009) “A imagem do adulto na contemporaneidade: uma avaliação dos jovens sobre os adultos".

No Google Acadêmico, as mesmas combinações de palavras, nas primeiras 500 entradas, remeteram também a três trabalhos relevantes, sendo que dois versam sobre uma mesma pesquisa, do mesmo ponto de vista, tratando-se de uma apresentação oral e de um artigo de mesma autoria. São eles (SOUSA, 2007) "O que é ser adulto: as práticas e representações sociais sobre 'O que é ser adulto' na sociedade portuguesa"; (SOUSA, 2004) "O que é ser adulto? As velhas e novas representações sociais sobre o que é ser adulto" e (SANTOS, ALÉSSIO e ALBUQUERQUE, 2007) "Adultos e jovens: diferentes olhares sobre o desenvolvimento". Assim, voltamos ao número dois e à mesma proporção encontrada no Dédalus: a cada $250^{2}$ texto localizado por palavras-chave inevitáveis, encontra-se um sobre o tema em pauta.

Por outro lado, quando se trata de estudos sobre adolescência, adolescentes, juventude sob as mais diversas perspectivas, esses abundam e explicitam o grande interesse que esse período desperta.

Em 1904, Hall publica "Adolescence: Its Psychology and Its Relations to Physiology, Anthropology, Sociology, Sex, Crime, Religion, and Education", o primeiro livro dedicado ao estudo psicológico desse período da vida. Autor da expressão stress-and-storm, para definir a adolescência, descrita como período de conflitos e de riscos, Hall apresenta o adolescente como dotado de sensibilidade, de vida interior intensa e de disposição para a reflexão sobre os próprios sentimentos. O adolescente é pensado em oposição à criança, pelo ponto de vista das mudanças pelas quais passa, em relação à fase anterior de sua vida, até alcançar a plenitude, isto é, a idade adulta. A vida adulta, convém destacar, é apresentada como referência, modelo de conduta a se atingir ao final do processo evolutivo.

Nesse estudo inaugural, tornar-se adulto é posto como o objetivo inconteste do jovem, pois o adulto é o parâmetro do sucesso de seu desenvolvimento. Tal visada permanece predominante, na quase totalidade dos trabalhos sobre o tema, até os dias de hoje.

\footnotetext{
${ }^{1}$ Catálogo on-line global das bibliotecas da USP.

http://dedalus.usp.br:4500/ALEPH/por/USP/USP/DEDALUS/START, acessado no dia 16/01/2010.

${ }^{2}$ Lembremos que, nos registros do Dédalus, o terceiro título foi descartado por ser de nossa autoria.
}

Disponível em: http://seer.fclar.unesp.br/casa 
Com frequência avassaladora, nos textos a que se pode ter acesso pelo Dédalus ou pelo Google Acadêmico, o jovem focalizado é desestabilizado ou dotado de frágil equilíbrio emocional, em decorrência de importantes mudanças internas e externas. Temas privilegiados são a gravidez adolescente, as drogas, a delinquência. Parte das publicações também relata, explica ou discute a compreensão de que esse período da vida deve seu contorno à industrialização e à legislação orientada ao cultivo de sociedades industriais estáveis, pela regulamentação de questões como trabalho infantil e educação compulsória.

A partir dos anos 50, diante do desenvolvimento tecnológico, o período pósinfância e pré-adultez ${ }^{3}$ começa a se alongar (COTE \& ALLAHAR, 1995, p. XV). A entrada no mercado de trabalho sendo adiada, mais tempo o jovem leva para conquistar sua independência, o que o mantém, mais longamente, morando na casa dos pais, na situação de filho não emancipado.

Nas áreas da saúde e da sociologia, os últimos sessenta anos foram palco de um sem-número de estudos voltados à compreensão da categoria "adolescente" (COTE \& ALLAHAR, 1995). Na literatura, não se pode passar ao largo de Holden, personagem ícone criada por Salinger, ${ }^{4}$ jovem em pleno turbilhão afetivo e cognitivo.

Foco de diversas visadas teóricas, o jovem é perscrutado, auscultado, analisado. Nesse seu "entre-lugar", entendido como no regime do "não mais" e do "ainda não", 5 o jovem é estudado, insistimos, a partir do lugar do adulto ${ }^{6}$ - o "ainda não" -, do ponto de vista das transformações, conquistas e dificuldades não conhecidas da criança - o "não mais".

Esse sujeito, cujo cérebro fervilha, formula hipóteses sobre si e sobre os outros, sopesa ideias e ações. Saiu da infância e vai ser adulto, mas, no último meio século, a linha fronteiriça entre as idades perdeu a nitidez, tornou-lhe acessível muito do que era particular ao mundo adulto (sexo, direito a voto, liberdade de escolha, consumo, poder de decisão sobre emprego do tempo etc.), modificou seu universo de possíveis e a abrangência de sua ação. Nesse novo contexto, o jovem tem a seu alcance muitas das antigas prerrogativas do adulto que, vale dizer, contribuíam fortemente para a caracterização deste e provocavam naquele o anseio de crescer e amadurecer. Desse modo, mesmo que pouco se tenha pesquisado sobre a adultez, as diferenças entre a juventude e a idade adulta, nesse intervalo de 60 anos, não se mantiveram as mesmas. Por isso, instigam o entendimento das representações que jovens contemporâneos fazem sobre esse período anterior à velhice.

\begin{abstract}
Almeida e Santos (1998) chamam a atenção para o fato de que o desenvolvimento humano é, em geral, compreendido tanto na literatura científica quanto nas teorias de senso comum, como uma sucessão de fases que caminham rumo a um objetivo final. A Psicologia, durante muitos anos, limitou o estudo do desenvolvimento humano à infância e à adolescência. Parece subjacente a essa postura a concepção de que a vida adulta seria o "período optimal", no sentido do ápice do desenvolvimento. Todas as outras fases seriam avaliadas em função do modelo adulto. (SANTOS; ALÉSSIO; ALBUQUERQUE, 2007, p. 107).
\end{abstract}

\footnotetext{
3 Embora inexistente no Houaiss (2001), esse é o termo empregado para denominar, na parca literatura acadêmica, o período que cobre da idade adulta até a velhice.

${ }^{4}$ Autor de Catcher in the Rye, falecido em 2010.

5 Isto é, "não mais" criança e "ainda não" adulto. De memória, paráfrase de Sartre, em L'être et Le Néant, ao tratar a vergonha existencial. Não está localizado no espesso volume, nesta ocasião.

${ }^{6}$ Não nos referimos, aqui, ao fato de as pesquisas serem realizadas por adultos, mas a serem pautadas pela adoção de uma ideia de "adulto" assumida como estabelecida, dada, ponto ótimo do desenvolvimento, não sujeita a discussões, fase de estabilidade, de ausência de mudanças. As exceções ainda são raras.
}

Disponível em: http://seer.fclar.unesp.br/casa 
Constatamos, junto com as autoras do excerto citado, que o ser adulto não tem despertado curiosidade acadêmica. Em Houaiss, parte de sua definição traz "que ou o que atingiu o máximo do seu crescimento e a plenitude de suas funções biológicas; que ou aquele que é emocional e intelectualmente maduro, que demonstra capacidade de agir, pensar e realizar algo de maneira racional, equilibrada, sensata". O adulto é, portanto, associado a máximo, plenitude, maturidade emocional e intelectual, razão, equilíbrio, sensatez. Mais adiante, perfeição é evocada, na definição do emprego figurado.

Ora, o fazer acadêmico-científico dá provas de que desconfiar de certezas pode ser revelador. Assim, o intento do presente trabalho é submeter esse ponto pacífico à prova do dizer de jovens, a fim de conferir se, sim ou não, o adulto "dicionarizado" corresponde à representação daqueles que caminham em direção a sê-lo. Importa também verificar se, entre as idades de 16 a 25 anos, a representação do adulto permanece fixa ou se é vista em processo, como acompanhando as transformações vividas pelo jovem. E, ainda, admitindo-se a hipótese da mutabilidade, necessário será pesquisar se as diferentes imagens resultam de reflexão individual, ou se apontam a uma gênese compartilhada, vinculada ao amadurecimento e à vivência do jovem.

$\mathrm{O}$ estudo aqui apresentado resulta de uma parceria franco-brasileira e propõe conjugar o olhar da semiótica francesa e o da psicologia do desenvolvimento. Tem como objetivo a investigação das representações do adulto construídas e projetadas no e pelo discurso de jovens mulheres a partir de entrevistas coletadas em Rennes, França, em 2007.

A investigação das representações juvenis sobre o que é ser adulto gerará informações sobre a adultez e fomentará reflexões sobre a adolescência e a sociedade em que o conjunto de entrevistas foi colhido, na primeira década do século XXI.

\section{Fundamentação teórica}

Análises das relações entre narrativas sobre si e sentido de identidade não são total novidade no campo da Psicologia, como mostram Hermans, Kempen e Van Loon (1992), Hermans e Kempen (1993), Hermans e Hermans-Jansen (1995), Mc Adams (1997, 2001), Robinson e Taylor (1998), entre outros. Não se encontram registros, no entanto, de parcerias em que análises semiótico-discursivas de linha greimasiana venham em subsídio a investigações psicológicas.

Primeiramente, apoiamo-nos em Ricoeur (1984, 2004), ao sustentar, fundamentado em Greimas (1970), que "identidade" somente existe em forma de narrativa, que a ideia que o sujeito faz de si e dos outros é dependente das historias que conta sobre si e sobre outrem e que outrem conta sobre ele. Franco $(2007$, p. 2) enfatiza a riqueza e o talento de "Ricoeur (1969, 1980, 1987, 1990, 2000, 2003), que criou uma abordagem original para o estudo da questão da identidade e alteridade, com base na história de vida e na história social, no testemunho e na representação, na linguagem, na cultura e na narração".

Ainda com Ricoeur (2004), admitimos que a identidade formula-se na tensão dialética entre o eu e o alter e entre o idem e o ipse, sendo o idem constituído por características inerentes ao sujeito e o ipse, componente sócio-histórico, resultante das negociações do sujeito com outros sujeitos no período em que vive. Decorre daí a posição aqui assumida de que a fala revela mais do que aquilo a que se propõe: ao falar de algo ou alguém, o sujeito se fala por meio de suas escolhas linguísticas, o que transparece com clareza já no léxico empregado, embora não apenas. 
Para a análise discursiva do corpus, composto de entrevistas orais, além dessas reflexões em torno de identidade narrativa, adota-se como orientação teórica, principalmente, as ideias desenvolvidas por Greimas (1970), Greimas e Fontanille (1991), Zilberberg (2006), Landowski (2006) e Barros (2008), na busca da elucidação dos modos de ancoragem das ações e das relações sociais nas imagens projetadas de si e de outrem.

A teoria semiótica francesa postula um percurso gerativo de sentido dotado de três níveis: fundamental, narrativo e discursivo. É no nível discursivo que os sujeitos do discurso se tornam atores, num espaço e tempo. É também nele que se inscrevem os valores sociais, as marcas ideológicas, enfim, é em seu bojo que um recorte do "mundo" se estabelece por meio das escolhas lexicais e figuras de linguagem. O nível narrativo é mais abstrato, é o lugar das relações intersubjetivas ou entre sujeitos e objetos, nível das transformações de estado, pelo fazer de um sujeito. O nível fundamental, como o próprio nome sugere, é o mais profundo e abstrato. É onde se colocam as relações de presença e ausência que caracterizam uma categoria central ao texto sob análise, tais como "natureza-cultura", ou "morte-vida". Os níveis fundamental e narrativo podem ser e, por vezes, são considerados conjuntamente, como nível "semionarrativo". Tal se deve às relações fundantes e intrincadas que mantêm, como Fiorin (1999) exemplifica:

A categoria euforia/disforia do nível fundamental converte-se em traços modais que modificam as relações entre sujeito e objeto. Assim, um valor marcado euforicamente no nível fundamental converte-se, por exemplo, em objeto desejável no nível narrativo, enquanto um valor disfórico torna-se, por exemplo, um objeto temido no nível narrativo.

Na passagem do nível semionarrativo ao nível discursivo, o objeto desejável ou temível, isto é, o objeto de valor, será revestido de uma gama de propriedades semânticas e ser entendido como coisa ou pessoa, num dado tempo e lugar. Alguns exemplos de objetos de valor eufórico podem ser: um carro esporte, ambicionado por um garoto; um pedaço de pizza fumegando para um paulistano na noite de um sábado frio; o petróleo do pré-sal no Brasil de 2010 etc. Paralelamente, um trovão, um engano, uma doença, a perda da face (no sentido empregado por Goffman, 1959), uma arma etc. são alguns exemplos de objetos de valor disfórico ${ }^{7}$.

Outra questão teórica necessária de se retomar, antes de descrever os procedimentos metodológicos, decorre do fato de que o corpus foi analisado diretamente a partir de seu registro oral. Inicialmente, pensava-se em transcrevê-lo, o que foi feito apenas em parte, devido a inúmeras dificuldades de ordem prática e de pessoal. ${ }^{8} \mathrm{O}$ trabalho sobre registro escrito cedeu lugar à análise de trechos enriquecidos das características prosódicas.

$O$ registro oral de uma entrevista não deixa de ser um congelamento de sua enunciação, compreendida enquanto ato ou processo de comunicação e de produção. Particularmente, aqui, interessa tomar-se a enunciação como ato que ativa a língua, que a põe em funcionamento, produzindo um ou mais enunciados. A enunciação nunca se repete, pois amarra à situação de sua produção suas referências a pessoa-tempo-lugar. É, portanto, única,

\footnotetext{
${ }^{7}$ Um objeto gozará de valor positivo ou negativo dependendo das coordenadas ideológicas dos sujeitos e da situação em que se insere. Um revólver, para um transgressor da lei, adquirirá possivelmente valor positivo, enquanto o mesmo objeto, no contexto escolar, por exemplo, terá valor disfórico.

${ }^{8}$ Agradeço, aqui, à colega e amiga Cristina Casadei Pietraroia, professora da área de francês da USP, o seu grande empenho em buscar a ajuda de alunos para as transcrições. Agradeço também a Sahsha Kiyoko Watanabe Dellatorre, aluna que fez a transcrição de uma longa entrevista.
} 
intangível e somente concebível como um ato linguístico pressuposto por seu produto, o enunciado, este, sim, analisável.

Se a enunciação é única, então os eu-aqui-agora repetidos ao longo das entrevistas não têm o mesmo valor que os do momento da enunciação: o aqui pronunciado refere-se à cidade de Rennes (um lá, para o analista); o hoje (um então, para o analista), ao dia da entrevista; o tu/você, grosso modo, à entrevistadora - são referências que permitem ao pesquisador recuperar a instância da enunciação. A enunciação "congelada" não se confunde com a enunciação propriamente dita. Nem é necessário destacar que tais referências são distintas das relativas ao eu-aqui-agora da realidade, suas coordenadas, seu tempo e lugar. Esclarece-se, então, porque somente enunciados, espaço de debreagens, são analisáveis. ${ }^{9}$

As debreagens se subdividem em dois grupos. Quando, no enunciado, as pessoas (eu/tu), o espaço (aqui) e o tempo (agora) da enunciação são instalados, trata-se de uma debreagem enunciativa, responsável pelo efeito de sentido de subjetividade. Quando o que se dá é instalação das pessoas (ele), do espaço (lá ou alhures) e do tempo (então) do enunciado, tem-se uma debreagem enunciva, por sua vez, instauradora do efeito de sentido de objetividade. $^{10}$

Isso posto, de posse das entrevistas, os esforços se concentraram na busca de informações passíveis de apoiar e enriquecer a análise de cunho psicológico na empreitada pela definição contemporânea do que é ser adulto. Assim, no nível discursivo, procedeu-se ao (a) levantamento dos temas tratados e das figuras empregadas pelas jovens entrevistadas. Estes foram (b) destacados e anotados como eufóricos, disfóricos ou outros, ${ }^{11}$ e (c) classificados como apresentados em debreagem enunciativa ou debreagem enunciva. Analisaram-se também as operações de (d) aspectualização e (e) moralização e, no nível semionarrativo, (f) a relação de junção entre sujeito e objetos, (g) as modalizações que as regem e as (h) oposições fundamentais na base das entrevistas.

\section{Método}

Estudantes da Université de Rennes 2 registraram entrevistas com cerca de uma centena de jovens entre 16 e 25 anos sobre "o que é ser adulto" como parte das atividades de formação em Psicologia, no âmbito do laboratório Dynamiques de la construction de soi ${ }^{12}$, em 2007.

A faixa etária escolhida abarca um ano além da definição da categoria jovem como pessoas entre 15 e 24 anos, colocada por ocasião do Ano Internacional da Juventude, em 1985, pela Assembleia Geral da ONU, e reafirmada posteriormente. Em 2000, a CEPAL ${ }^{13}$ reafirma a faixa etária definida, em 1985, e enfatiza que

\footnotetext{
${ }^{9} \mathrm{O}$ conceito de breagem recobre a categoria embreagem-debreagem. O primeiro termo diz respeito ao eu-aquiagora da enunciação e o segundo se coloca no nível dos enunciados.

${ }^{10}$ Para análise profunda dos diferentes tipos de debreagens, ver Fiorin (1996).

${ }^{11}$ Não distinguimos, para este fỉm, os não eufóricos e não disfóricos.

12 Coordenado por Françoise Bariaud, o eixo pertinente é localizado em <http://www.sites.univrennes2.fr/crpcc/index.php?rep=axes\&rub=construction_soi>, acessado em 30 ago. 2010.

${ }^{13}$ A Comissão Econômica para a América Latina (CEPAL) foi estabelecida pela resolução 106 (VI) do Conselho Econômico e Social, em 25 de fevereiro de 1948, e suas operações iniciadas no mesmo ano. Em 1984, por meio da resolução de 27 de julho de 1984, o Conselho decidiu que a Comissão seria renomeada para a Comissão Econômica para a América Latina e o Caribe. A CEPAL, cuja sede é em Santiago, Chile, é uma das cinco comissões regionais das Nações Unidas.
} 
[...] o entorno etário escolhido é baseado em fundamentos apropriados, pois as entradas e saídas dessa fase coincidem com importantes períodos de transição no ciclo de vida. O limite inferior [15 anos] considera a idade em que já estão desenvolvidas as funções sexuais e reprodutivas, que diferenciam o adolescente da criança e repercutem na sua dinâmica física, biológica e psicológica. O limite superior [24 anos] diz respeito ao momento em que os indivíduos normalmente concluem o ciclo da educação formal, passam a fazer parte do mercado de trabalho e constituem suas próprias famílias, caracterizando assim, de forma simplificada, a transição para a fase adulta (AVILA, 2005, p. 2).

As gravações foram posteriormente triadas pelos critérios de qualidade sonora, compreensibilidade e relevância do conteúdo de fato desenvolvido, gerando um conjunto, em quase sua totalidade, respondido por jovens mulheres. Optou-se, então, por limitar o corpus a respondentes do sexo feminino de maneira a formar três grupos etários relativamente equilibrados, G1, G2 e G3, correspondendo respectivamente a 16, 20 e 25 anos de idade ${ }^{14}$. Assim, foram analisados quatorze documentos sonoros, a fim de depreender-se o sujeito do discurso e marcas discursivas relativas ao tema em pauta, com o objetivo de verificar que representações o jovem faz do adulto.

As produções discursivas internas a cada faixa etária foram analisadas pela perspectiva da semiótica discursiva e comparadas em busca de regularidades. Resultaram do procedimento as ocorrências reiteradas, o que permitiu esboçar um conjunto de representações do adulto para cada grupo etário.

Finalmente, o cotejo de tais representações produziu uma ideia geral do adulto, conforme construída discursivamente pelas jovens participantes.

Utilizou-se a técnica de entrevista compreensiva ${ }^{15}$ (KAUFMANN, 1996), guiada por perguntas. Em conversas informais e motivadas de duração entre 15 e 45 minutos, solicitou-se às entrevistadas que discorressem sobre o tema em pauta a partir de um roteiro de questões como apoio. $\mathrm{O}$ emprego de um roteiro se justifica por, ao menos, três aspectos:

a) as perguntas proporcionam manutenção da conversa com entrevistadas pouco falantes;

b) as questões têm o papel de recurso de limitação de fugas do tema e de chamada de volta ao assunto;

c) um roteiro de questões garante certo grau de homogeneidade dos conteúdos tratados e contribui para o estabelecimento de um corpus dotado de coerência interna.

Para cada grupo etário o roteiro, apresentado a seguir, consistiu em quatro ou cinco perguntas.

\footnotetext{
${ }^{14}$ Especificando, G1 continha as entrevistas de LOU, 16, MDA, 16 e ION, 17, estudantes do equivalente ao ciclo médio; G2, de CAM, 20, SOP, 20, MAG, 18, BLA, 22 e STE, 20, todas estudantes em cursos técnicos de nível superior ou em faculdades; e G3, de MIC, 25, PER, 25, SON, 25, EMA, 25, CAT, 25, MIR, 25, as cinco primeiras universitárias e a última, MIR, 25, a única que trabalhava e era mãe.

${ }^{15}$ Utilizamos aqui o termo no sentido weberiano, a partir de Kaufmann (1996), significando um tipo de entrevista que é um instrumento integrante na construção do objeto pesquisado e cujas questões, previamente definidas, podem sofrer alterações conforme o direcionamento que a investigação toma. É uma entrevista não estruturada, que se constrói no diálogo entre entrevistado e pesquisador.
} 


\section{Roteiro-base para entrevistas com jovens mulheres, na cidade de Rennes, $2007^{16}$}

\section{Para as jovens de 16 anos}

- O que significa ser adulto, para você?

- Em que idade alguém se torna adulto para você?

- Tente se imaginar aos....... (a idade em que pensa que se é um adulto em relação à pergunta anterior), o que terá mudado?

- Quais são as mudanças mais importantes entre você agora e o que você imagina ser aos 20 ?

\section{Para as jovens de 20 anos}

- O que significa ser adulto para você?

- Você se sente adulta? O que a faz dizer isso?

- Você tem vontade de ser adulta?

- Como você via o adulto aos 16 anos?

- Há acontecimentos importantes que a fizeram achar que se tornava adulta?

\section{Para as jovens de 25 anos}

- O que significa ser adulto para você?

- Você se considera adulta? O que a faz dizer isso?

- O que faz/faria você (critérios) considerar-se plenamente adulta?

- Aos 20, você via o adulto do mesmo modo que o vê agora?

- Quando você pensa sobre seu crescimento, houve acontecimentos significativos, que fizeram com que você se sentisse adulta? (tradução nossa)

\section{Resultados}

\footnotetext{
"Je ne pense pas que ça soit une question d'âge, je pense que c'est plus une question de maturité »

"Quand on est adulte, on a la liberté de vivre heureux, d'avoir la voiture qu'on veut et tout...»

"ça dépend du regard des autres aussi » "quand on est enfant on voit l'adulte comme quelqu'un un peu fade »
}

\footnotetext{
${ }^{16}$ 1. Pour les jeunes filles de 16 ans: Etre adulte, qu'est ce que cela signifie pour toi? / A quel âge est-on adulte pour toi? / Essaie de t'imaginer à...... (l'âge auquel elle pense que l'on est adulte en rapport avec la question précédente), qu'est-ce qui aura changé? / Quels sont les changements les plus importants entre ce que tu est maintenant et ce que tu imagines être à 20 ans?

2. Pour les jeunes filles de 20 ans: Etre adulte, qu'est ce que cela signifie pour toi? / Tu te sens adulte? Qu'estce qui t'amène à dire ça? / As-tu envie d'être adulte? / Comment tu voyais l'adulte à 16 ans? Il y a t-il des évèvements forts qui t'on donné le sentiment que tu devenais adulte?

3. Pour les jeunes femmes de 25 ans: Être adulte, qu'est ce que cela signifie pour toi? / Te considères tu comme un adulte? Qu'est-ce qui t'amène à dire ça? / Qu'est ce qui t'amènerait (critères) à te considérer pleinement comme adulte? / A 20 ans, tu voyais l'adulte de telle manière, et maintenant, le vois-tu de la même façon? I Quand tu penses à la façon dont tu as évolué, est-ce-qu'il y a eu des évènements importants, pour toi, qui t'on donné le sentiment de devenir adulte?
} 
Dois temas complementares surgem em resposta à primeira pergunta ${ }^{17} \mathrm{e}$ permeiam as colocações das entrevistadas: por um lado, aspectos pessoais, afetivos, humanos e, por outro, sociais, públicos, administrativos. "Ser adulto" exige atender-se a um número de condições em cada uma das áreas: é ser independente, responsável e autônomo financeiramente; é dar o exemplo, lutar, perseverar e tomar decisões (certas); é também "assentar-se", acalmar-se, tornar-se sério, saber usar seu tempo, saber "o que a vida significa"; ${ }^{18}$ ser eficiente, tranquilo, mais reflexivo; constituir família.

As entrevistas iniciam-se nesse registro previsível de características usualmente atribuídas ao adulto e dele cobradas. Quando perguntadas ${ }^{19}$ sobre se sentirem ou não adultas, as integrantes de G2 (20 anos) reconhecem-se em transição, porém cobradas socialmente por comportamentos e posturas maduras, aos quais se adaptam, mas dos quais prefeririam se ver livres. No primeiro momento, longe das restrições sociais, dizem-se aliviadas por poderem ser "ela[s] mesma[s]". Entende-se que se mostram adultas devido à pressão social, mas não se sentem adultas. As jovens de G3 (25 anos) consideram-se quase adultas. Três delas iniciam a entrevista assumindo a adultez, todavia, ao longo da conversa, somente uma mantém a posição inicial, e cinco se assumem "não adultas". Também se sentem cobradas pela sociedade por comportamentos adultos, criticadas se não corresponderem e aliviadas quando distante dos olhos judicativos por poderem ser espontâneas. Para a metade das entrevistadas de G3, ter um filho e cuidar dele é o que transforma alguém realmente em adulto. Quanto a G1 (16 anos), alguém se torna adulto por volta dos 30 anos. Nenhuma integrante de G1 assume ter vontade de corresponder à imagem do adulto. LOU arrisca afirmar que, avec un peu de chance, será adulta lá por seus 30 anos.

Outra colocação comum é a associação do direito à felicidade na idade adulta, com a liberdade de ter: a ausência de ponderações de ordem política, social ou econômica esboça o adulto como aquele que teria a seu alcance a escolha de carro, emprego, casa segundo seus desejos, assim como a escolha de ter família, filhos, cachorro etc.

\section{Das oposições fundamentais aos regimes de junção e suas manifestações figurativas}

Nas entrevistas, repetem-se oposições fundamentais que definem a passagem de jovem a adulto: de um lado, a "liberdade" e a "abertura"; de outro, a "opressão" e o "fechamento". Os valores eufóricos expressam-se predominantemente pela modalidade do querer e sua realização constitui o universo juvenil, euforizado pela abertura e pela liberdade. Contrariamente, os valores disfóricos associam-se à modalidade do dever, cuja imposição estabelece e caracteriza o universo adulto, disforizado pela opressão das obrigações e pelo fechamento. Muda-se, portanto, a perspectiva: no lugar de o jovem ser pensado a partir do adulto, como normalmente vemos nas pesquisas e dicionários, é o ser adulto que se coloca pela negação do que é ser jovem.

As ações e atitudes cuja realização é apresentada como típica do jovem, ou sua figurativização, são: sair para todo lado, mexer-se, ir, divertir-se, aproveitar tudo, viver o momento, rir, sonhar, sentir, brincar, ser espontâneo, sempre descobrir muitas coisas, deixar-

\footnotetext{
${ }^{17} \mathrm{O}$ que significa ser adulto para você?

${ }^{18}$ Savoir ce que la vie signifie é, ipsis literis, fala de LOU, 16 anos. Todas as traduções de trechos da entrevista são de minha responsabilidade.

${ }^{19}$ Faixa etária 1: Em que idade alguém se torna adulto para você? / Faixas etárias 2 e 3: O que significa ser adulto para você? 
se encantar por muitas coisas. $^{20}$ Ser jovem é estar conjunto dessas realizações, todas modalizadas pelo querer; ser jovem, enfim, é ser permeável e, assim, realizar seus quereres aspectualizados como fim último do viver. Paralelamente, aquilo que o jovem quer não fazer, ou as ações também modalizadas pelo querer, mas cuja realização é recusada, são: ter a vida estabelecida de modo que nada de novo aconteça, ter medo do futuro, assentar-se, perder a capacidade de se surpreender, ter uma vidinha aos 30 anos com "filho, marido e cachorro", cair na rotina, perder a despreocupação, a leveza ${ }^{21}$.

Se, para o jovem, o querer domina, para o adulto, a vida é fortemente modalizada pelo dever. Além de dever ter emprego, família, casa, autonomia, independência, tranquilidade, maturidade, personalidade definida, seriedade, o adulto deve conhecer as respostas a perguntas existenciais tais como: que sou? quem sou? para onde estou indo? de onde venho? Deve também saber gerir tudo sozinho: a vida cotidiana, consertos da casa, imposto de renda, a vida dos filhos, a relação com o cônjuge, o emprego de seu tempo, as compras, os pagamentos, a conta bancária, inquietações pessoais, dúvidas, a própria atenção, sempre voltada a uma porção de coisas. Para ou por dar conta de tudo isso, disjunge-se da liberdade $^{22}$ e da "abertura". Limita sua vida social: de grupos de amigos, a um ou dois pequenos grupos ou casais, até a uma, outra ou mesmo nenhuma amizade; os pais vão para os bastidores; tem mais dificuldade em manter vínculos afetivos e em restabelecer vínculos abalados; cada vez mais raramente faz novos amigos. Igualmente, limita-se sua vida afetiva e pessoal: casais adultos conversam cada vez menos sobre si; cada vez há menos pessoas a apoiá-lo; é cada vez mais difícil pedir ajuda. Limita-se, também, o escopo de seu olhar: tudo é visto "por óculos" sexuais: muitos adultos não conseguem entender uma amizade entre garoto e garota. Enfim, o caminho do adultecer é prenhe de perdas, desgastes e limitações, mesmo se, aqui e ali, respingam algumas afirmações do tipo "ser adulto é como um sonho, poder fazer o que quiser...".

A gama de deveres e responsabilidades e o estreitamento de possibilidades e interesses, contudo, não bastam para esboçar o ser adulto. Além dessas questões, ou devido a elas, a pessoa perde gradativamente o direito de perder tempo, o direito ao erro, o direito a uma segunda chance, o direito ao perdão por besteiras e por coisas sérias... até mesmo o direito à queixa pelas perdas.

Enfim, ser adulto exige "batalhar incessantemente"23. Com alguma sorte, encontra-se "a pessoa certa", "um cara com quem partilhar a vida", e, evitando-se a rotina e continuando a ter projetos, investindo afetivamente no casal ou na família, viajando, encontrando pessoas, o adulto poderá ser feliz, aproveitar seu tempo e ter coisas a dizer, bagagem, experiência. Isso, porém, foge à regra, é coisa para poucos. Para a grande maioria, o período da adultez é cada vez mais sombrio, isolado, solitário.

\footnotetext{
${ }^{20}$ As espressões utilizadas são: sortir à droite et à gauche; sortir comme um fou, bouger, aller, s'amuser, profiter de tout, prendre le moment comme il vient, rire, rêver, sentir, rigoler, être spontanée, découvrir toujours plein de choses, se laisser s'émerveiller par beaucoup de choses.

${ }^{21}$ Expressas por: avoir la vie bien définie, avoir peur de l'avenir, être posée, avoir une petite vie à 30 ans, "enfants, mari, chien", tomber dans la rotine, perdre l'insouciance, la légèreté.

${ }^{22}$ Expressões empregadas nas diferentes entrevistas: On est moin libre. On n'est pas libre. Convém ressaltar que as mesmas entrevistadas podem dizer que o adulto tem mais liberdade e, posteriormente, que é menos livre. Interessantemente, o adulto é considerado como tendo liberdade no universo do ter, porém, ele não é livre, isto é, seu poder não atinge o ser, ou aquilo que acredita ser.

23 "se battre sans cesse".
} 


\section{A subjetividade nas entrevistas}

«Je risque de tomber là dedans»

"C'est une autre vie»

“C'est quelqu'un qui [ne] s'émerveille plus sur de tas de choses»

"pour que tu sois adulte il [ne] faut pas... c'est comme si tu n'avais plus le droit... de rire, quoi»

"Terme grand, énorme"

"Ça me fait peur"

No cômputo geral, o preço de ser adulto é alto. O mais evidente é o temido "cair na rotina" por ser ela a raiz da dor e dos males do adultecer, segundo as entrevistadas.

É o momento de recordar que o efeito de sentido de subjetividade resulta do emprego, no enunciado, das pessoas (eu/tu), do espaço (aqui) e do tempo (agora) da enunciação e, de maneira complementar, o efeito de sentido de objetividade instala-se quando se têm, no enunciado, as pessoas (ele), o espaço (lá ou alhures) e o tempo (então) do enunciado.

A língua francesa reserva ao analista uma dificuldade especial: o pronome "on", que tanto pode remeter a um sujeito indefinido, às pessoas em geral (valor de ele, eles), quanto pode referir a própria pessoa, a pessoa a quem determinada fala é dirigida, ou a própria pessoa e seu grupo familiar ou de amigos (valor de eu, tu, nós, vós). A distinção entre esses dois grupos coincide com a clássica colocação de Benveniste (1966), segundo a qual as pessoas do discurso são instaladas pelos pronomes "eu", "tu" e as não pessoas, pelo pronome "ele", e constitui um elemento essencial ao efeito de sentido de subjetividade ou objetividade. Em princípio, "on" pode, a cada emprego, ser vetor de uma debreagem enunciva, geradora do efeito de sentido de objetividade ou de uma debreagem enunciativa, produtora do efeito de subjetividade.

O dicionário Larousse, tanto em edição impressa (de 1988) quanto virtual (www.larousse.fr/dictionnaires/français), define "on" por "pronome indefinido ou pronome pessoal". Sendo sempre sujeito, "on" designa um ser humano qualquer, pessoas cuja identidade não é conhecida ou precisa, pessoas distantes no tempo e no espaço, uma pessoa indeterminada em provérbio, ditos, frases de ordem em geral. Sem sombra de dúvida, equivalente a "ele" ou "eles", ou não pessoas. Adiante, complementa: em linguagem familiar, "on" remete ao falante e uma ou mais pessoas, ao falante e ao grupo ao qual pertence, ao falante como representando um sujeito masculino ou feminino e, finalmente, ao interlocutor do falante, ou ao falante e a seu interlocutor. Na linguagem do dia a dia, familiar, informal, "on" significa pessoa: "nós", "eu", "tu” ou "vós".

$\mathrm{O}$ corpus em foco traz linguagem marcadamente informal, entre jovens. Expressões tais como Salut" (Oi!), sympa (simpático/a), hyperbien (extremamente bom ou bem), superdure (muito difícil), hypersérieuse (muito séria), c'est pas mon truc (não me atrai) são frequentes, assim como risos, chistes e zombarias. Nesse universo, on é testemunho da subjetividade. LOU, 16, descreve-se: "Ainda não temos muitas preocupações"; CAM, 20, sobre a transição entre adolescência e idade adulta, sentencia: "a gente tem cada vez menos uma segunda chance"; e PER, 25, completa: "a gente é menos espontânea, não pode mais brincar." 24

\footnotetext{
${ }^{24}$ Respectivamente, “On n'est pas plein de soucis encore », " on a moins en moins une seconde chance », “on est moins spontanée, on ne peut plus rigoler”. 
Nas entrevistas, embora ocorram expressões de objetividade, predomina o universo da subjetividade. Quando caracterizado mais objetivamente, via debreagens enuncivas, (terceira pessoa do singular ou plural, ou on com esse valor), como por G1, ser adulto implica querer fazer ou criar algo; o adulto tem filhos e vida familiar, tem liberdade (de ter), mas não é livre, pois, responsável por si e pelos filhos, não pode sair a qualquer hora. Aos quarenta anos, é de se esperar que todos sejam adultos, mas, até os trinta, é possível não sê-lo. Já, aos vinte anos, só assume a vida de adulto quem não tem ambição. Para G2, o forte do adulto é seu lado moral e a passagem para a adultez se dá quando o sujeito faz o que quer e faz de tudo para consegui-lo. ${ }^{25}$ Por um lado, o adulto sabe tocar sua vida, sob todos os aspectos financeiros e relativos a trabalho, enquanto, por outro, questiona-se o tempo todo, principalmente sobre como empregar seu tempo, pois não pode se permitir desperdiçá-lo. Por isso, ele tem altos e baixos, sofre de stress, depressão, angústia. Finalmente, G3 configura o adulto como "alguém que não se encanta por muita coisa", ${ }^{26}$ alguém que perde a magia e a alegria. Interessantemente, PER, 25, destaca uma observação, no mínimo, curiosa, pois, segundo ela, "há um hiato entre os sexos, já que menos mulheres são adultas o tempo todo". 27

Nas debreagens enunciativas, que expressam maior grau de subjetividade, LOU, 16, define a palavra "adulto" como "um termo grande, enorme, que [lhe] causa medo". Segundo G1, quando alguém se torna adulto, as respostas a perguntas existenciais são compreendidas em troca da perda da liberdade anterior: não mais se aproveitam as coisas boas, não é mais possível viver a vida ou descobrir novos horizontes, pois o emprego do tempo se direciona à manutenção da família, dos filhos, da casa, do cachorro. ${ }^{28}$ Nunca mais vai levantar de manhã e decidir o que fazer: tudo será sempre cuidadosamente planejado, pois não pode perder tempo e tem de resolver tudo - aluguel, prestações, compras, seguro, impostos, decisões necessárias etc. - sozinho. Os quereres e a alegria da juventude perdem o lugar para a preocupação e o cumprimento dos deveres da vida adulta, cuja única liberdade passa a ser a de ter.

Do ponto de vista feminino, uma moça começa a se tornar adulta quando encontra "o companheiro certo/ideal", ${ }^{29}$ com quem inicia uma vida de casal. Ao terem filhos e se fixarem no emprego, a vida se estabiliza e não muda mais. Nada de novo, nenhuma descoberta, planos abandonados, dia a dia em direção à frustração, tristeza, angústia - eis o adulto pleno para olhos de dezesseis anos.

G2 acrescenta alguns traços ao quadro já esboçado, embora não lhe seja tema o conhecimento das respostas a perguntas existenciais. Ao imaginarem-se adultas, suas integrantes veem-se como alguém que precisa se esforçar sempre mais, que se torna cada vez mais só e que tem maior dificuldade para criar vínculos. A passagem para a idade adulta depende muito do olhar dos outros, que as faz se sentir restringidas em suas manifestações afetivas e obrigadas a assumir posturas convencionais, logo, artificiais. Como um sujeito em transição, manifesta certa vontade de se tornar adulta, porém com o firme propósito de manter as características de espontaneidade, alegria, vontade de se dar bem, de continuar a fazer projetos e a sonhar, ao contrário dos adultos normais, que perdem a alegria de viver, abandonam seus projetos, desistem de viver e de amar.

\footnotetext{
${ }^{25}$ Convém ressaltar que o fazer de tudo, para as entrevistadas, tem o sentido de esforço, determinação. Ele não implica burlar leis ou puxar tapetes.

26 «quelqu'un qui ne s'émerveille plus devant un tas de chose. »

27 «il y a un décalage entre les sexes, moins de femmes sont tout le temps adultes».

${ }^{28}$ As expresões "une petite vie" e "enfant, maison, chien" são empregadas por duas das entrevistadas, para se referir à vida rotineira de adulto.

29 "la bonne personne".
} 
Para G3, o adulto caminha em direção à autonomia, enquanto acumula cada vez mais deveres; perde a espontaneidade, o direito de rir e de se divertir e, pouco a pouco, a capacidade de sentir, amar, fazer projetos, sonhar. Dos três grupos, é o único a empregar maciçamente o "tu" no lugar de "ele". Ao discorrer sobre "o estado adulto", chega a abandonar a forma "o adulto + verbo $3^{\text {a }}$ pessoa" e a substituir por "tu + verbo em $2^{\text {a }}$ pessoa", como se o interlocutor não apenas falasse com seu interlocutário, mas sobre ele e trouxesse a cena enunciva para dentro da cena enunciativa, provocando um efeito de sentido, ao mesmo tempo, de generalização referenciada e de aproximação subjetiva, na busca da adesão do interlocutário. Tal substituição torna possível "pessoalizar enunciados impessoais. Esse sujeito, substituído por tu/você, mantém uma relação viva com a situação de enunciação como se fosse parte dela" (MAINGUENEAU, 1981, p.17).

Segundo G3, o adulto (você) necessita ter mais confiança em si e ganhar mais a confiança dos outros, pois vão perdoar-lhe ${ }^{30}$ menos e (você) só terá a si mesma com quem contar, uma vez que os pais saem de cena; ${ }^{31}$ precisará conter-se em manifestações afetivas, brincadeiras e risos, para não ser considerada infantil; (você) tem menos direito ao erro e sofre penas maiores, a exemplo da lei que pune, pelo mesmo delito, o adulto mais fortemente que o jovem. E, quando tem filhos, deve suportar o peso da responsabilidade só: em seis entrevistas distintas, em mais de 90 minutos, nenhuma referência é feita a um possível companheiro ou cônjuge com quem compartilharia o cometimento que constitui "o peso de um filho", nem mesmo por aquelas que são mães. Por outro lado, ao discorrer sobre projetos pessoais, a vida de casal ocupa posição de destaque e o companheiro tem lugar: na vida adulta, a jovem passa a morar com ele, compram coisas juntos, adquirem um imóvel em parceria, passam a dormir juntos habitualmente.

\section{Discussão dos resultados}

"franchement, plus tard que plus tôt... à 25 ans je pense pas être adulte, »

"je pense que peut-être à 30 ans j'aurai envie.. »

Retomemos aqui alguns dados. No início do item "Resultados", a concepção de "o que é ser adulto" esboça um sujeito amadurecido afetiva, pessoal e socialmente: ser adulto "é ser independente, responsável e autônomo, financeiramente; é dar o exemplo, lutar, perseverar e tomar decisões (certas); é também, tornar-se sério, saber usar seu tempo, saber "o que a vida significa"; ser eficiente, tranquilo, mais reflexivo; criar algo; constituir família" (p. 8).

Adiante, uma das entrevistadas afirma que "há um hiato entre os sexos, já que menos mulheres são adultas o tempo todo" (p. 11).

Ao longo das entrevistas, a idade adulta vai se tornando incerta: "a mulher adulta poderá ser feliz, aproveitar seu tempo e ter coisas a dizer, bagagem, experiência" se, "com alguma sorte, encontra[r] "a pessoa certa", "um cara com quem partilhar a vida" (p. 9) e com quem realizar projetos.

As três colocações anteriores figurativizam um modelo estereotipado de adulto, calcado na imagem masculina do provedor da família, em uma sociedade relativamente

\footnotetext{
30 Convém lembrar que respondem a uma entrevistadora, fato significante para o emprego exclusivo do feminino.

${ }^{31}$ Os pais, quando mencionados, estão sempre no registro do distanciamento, ou no da ausência, no processo de se tornar adulto.
} 
estável: forte, capaz, equilibrado, autônomo, sério, sabedor das respostas e acertado em suas decisões; o adulto construído pelas respondentes francesas coincide com os dados de Sousa $(2004,2007)$ em pesquisa sobre o que é ser adulto na sociedade portuguesa aos olhos de jovens.

Em outras palavras, para as jovens entrevistadas, o imaginário projetado do adulto é coincidente com o tradicional, ao ponto de uma delas afirmar que "menos mulheres são adultas o tempo todo". Um segundo dado a remeter ao ideário tradicional é o atrelamento da felicidade adulta à vida de casal idealizada: "trouver la bonne personne"; constituir família; compartilhar a vida com " $\boldsymbol{a}$ pessoa certa". ${ }^{32}$

Se o imaginário projetado do adulto coincide com o tradicional, o desejo expresso de não se tornar adulto/a introduz uma contradição. Ao longo das falas das entrevistadas, a vida adulta, inicialmente concebida como vida plena, cede o lugar para a luta cotidiana, a cobrança social e responsabilidades crescentes, até que essas, gradualmente, partilham o espaço com incertezas, frustrações, dificuldades, infelicidade e solidão.

Imanishi (2009) também encontra relutância, da parte de jovens brasileiros, diante do tornar-se adulto. Uma diferença notável entre seus achados e os deste estudo, contudo, não pode ser omitida: enquanto, para as francesas, a resistência mostrada à adultez possa ser atribuída à sua caracterização como período árduo, de luta cada vez mais intensa e solitária, para os 520 respondentes brasileiros, com dados obtidos por meio de questionário com respostas motivadas, tal resistência possa ser devida à uma má imagem do adulto em geral, uma vez que este é visto como não ético (60\%), incapaz de conduzir bem o mundo $(72 \%)$, incompetente no educar $(56 \%)$, inapto politicamente $(90 \%)$, egoísta $(56 \%)$ e como tendo no dinheiro o valor mais almejado para a vida $(73 \%)$. Desse modo, se o contexto francês separa jovens de adultos predominantemente pelas realizações modalizadas pelo querer e pelo dever, o contexto brasileiro os esboça sob forte moralização, no limite, no maniqueísmo típico de "bons versus maus", de jovens vitimados versus adultos algozes do futuro.

Voltando ao escopo deste estudo, isto é, ao contexto francês, a palavra que melhor define a adolescência para PER, 25, é "insouciance"33, traduzível por despreocupação, desprendimento, indiferença, certeza de receber cuidados se precisar. Tal noção, por sua vez, leva esse período da vida a ser percebido como o mundo da abertura, da alegria, do desejo, do companheirismo, da descoberta, enfim, como o mundo do acontecimento.

Enquanto, em seu próprio discurso, o jovem vive "livre, leve e solto" e, convém lembrar, dependente do adulto, este é caracterizado como submerso em deveres, transbordando de problemas e responsável pelos cuidados com os mais novos e com os mais velhos. É o mundo do fechamento, do cansaço, da crescente insatisfação e tristeza, do abortamento do desejo, da solidão, da rotina, enfim, o mundo da repetição. Em termos zilberberguianos, o mundo dos fatos:

[...] o acontecimento é o correlato hiperbólico do fato, assim como o fato se coloca como o diminutivo do acontecimento. Este é raro, quanto mais raro, mais importa: aquele que afirma sua importância notável do ponto de vista

\footnotetext{
${ }^{32}$ Embora não tenhamos dados para afirmar, suspeitamos que as jovens acabam por discorrer sobre o que é ser mulher adulta, tanto pela valorização da relação do casal, quanto pelo peso atribuído ao ter filhos.

${ }^{33}$ Em francês, a palavra empregara é "insouciance", que traduz um estilo de vida segundo o qual a pessoa não considera perigos, não se preocupa com nada, como se "flutuasse acima da realidade".
} 
tensivo afirma explicitamente ou tacitamente sua unidade do ponto de vista extensivo, enquanto o fato ${ }^{34}$ é numeroso. ${ }^{35}$ (ZILBERBERG, 2006).

Por esse viés, a adolescência é hiperbólica, pois tudo o que nela acontece tem valor de raro, enquanto a idade adulta consiste na diminutiva repetição cotidiana, no império dos fatos, dos duros fatos que atrofiam o viver e o transformam em rotina.

Oposição entre adolescência e vida adulta colocada, resta verificar se a representação da segunda corresponde à dicionarizada nas três faixas etárias, ou se é paulatinamente construída, conforme a hipótese posta no início deste artigo.

Resgatando-se as informações levantadas anteriormente, pode-se construir um quadro-resumo das formas, tanto da expressão quanto do conteúdo, preferidas de cada entrevistada em sua caracterização do adulto:

\begin{tabular}{|c|c|c|c|}
\hline \multicolumn{4}{|c|}{ Debreagem ${ }^{36}$ Enunciativa / Efeito de sentido de aproximação } \\
\hline & G1 ( 16) & G2 ( 20) & G3 ( 25) \\
\hline Figuras & $\begin{array}{l}\text { Alguém que você } \\
\text { ame e com quem } \\
\text { você faz sua vidinha, } \\
\text { vive sua paixão; } \\
\text { Se você encontra a } \\
\text { boa pessoa; } \\
\text { Vida de casal; } \\
\text { Tenho medo de ser } \\
\text { adulta. }\end{array}$ & $\begin{array}{l}\text { Você tem menos uma segunda } \\
\text { chance; } \\
\text { Você conta menos com pais; } \\
\text { Sai do casulo familiar; } \\
\text { Tenho medo de cair na rotina; } \\
\text { Quanto mais crescimento, mais } \\
\text { responsabilidade você tem; } \\
\text { Dá medo tomar consciência; } \\
\text { Tenho medo do futuro; } \\
\text {...aí você vai compreendendo porque } \\
\text { muitos adultos não foram bem } \\
\text { sucedidos em seus projetos; } \\
\text {...no momento em que você faz o } \\
\text { que quer e faz tudo para consegui-lo, } \\
\text { você é adulto. } \\
\text {...quero levar alegria da infância para } \\
\text { a idade adulta; } \\
\text {... não quero perder sonho, alegria. }\end{array}$ & $\begin{array}{l}\text {...é como se você não tivesse } \\
\text { mais o direito de rir; } \\
\text { Você tem menos direito a } \\
\text { perdão por besteiras; } \\
\text { Os outros cobram seu } \\
\text { comportamento; } \\
\text { Você deixa de ser livre, } \\
\text { porque outros dependem de } \\
\text { você; } \\
\text {...não pode mais ser } \\
\text { espontânea; precisa ter } \\
\text { conversa séria; } \\
\text { É necessário se assentar; } \\
\text { acalmar-se; } \\
\text {...quero viver minha vida } \\
\text { tranquila } \\
\text {...quero continuar deixando } \\
\text { aflorar "ma gamine"; } \\
\text {...quero poder sair, sentir, } \\
\text { divertir-me, ser espontânea; } \\
\text {...quero continuar a fazer o } \\
\text { que quero quando quero; } \\
\text { Não tenho vontade de me }\end{array}$ \\
\hline
\end{tabular}

${ }^{34}$ Os conceitos que, nesse texto, Zilberberg trabalha como "acontecimento" e "fato", originam-se como os termos "éclat" e "répétition", apresentados em primeira mão em uma palestra, em final de 1993, nos Seminários de Semiótica, na Maison de l'Amérique Latine, Paris. Os termos antigos também se aplicariam com perfeição à adolescência e à idade adulta.

35 ... l'événement est le corrélat hyperbolique du fait, de même que le fait s'inscrit comme le diminutif de l'événement. Ce dernier est rare, d'autant plus rare qu'il importe: celui qui affirme son importance insigne du point de vue intensif affirme explicitement ou tacitement son unicité du point de vue extensif, tandis que le fait est nombreux. (T. do A.)

${ }^{36}$ Não serão considerados os graus das debreagens, uma vez que nosso interesse recai sobre a colocação do contexto da enunciação ou do enunciado e seus efeitos de sentido de aproximação, subjetividade e "realidade" ou distanciamento e objetividade.

${ }^{37}$ A palavra "tranquille" evoca uma situação financeira sem problemas. 


\begin{tabular}{|l|l|l|l|}
\hline \multirow{7}{*}{} & & & $\begin{array}{l}\text { tornar adulta; } \\
\text { Não sei se um dia a gente } \\
\text { pode se considerar adulta, a } \\
\text { não ser quando se tem filhos; } \\
\text { Ter meu filho foi um grande } \\
\text { passo, para eu começar a me } \\
\text { sentir adulta. }\end{array}$ \\
\hline Temas & Amor & $\begin{array}{l}\text { Conservação /Mudança } \\
\text { Perdas } \\
\text { Pressão social } \\
\text { Contenção }\end{array}$ \\
\hline
\end{tabular}

Quadro 1: Resumo das ocorrências de debreagem enunciativa.

\begin{tabular}{|c|c|c|c|}
\hline & \multicolumn{3}{|c|}{ Debreagem enunciva / Efeito de sentido de distanciamento } \\
\hline & G1 & G2 & G3 \\
\hline Figuras & $\begin{array}{l}\text { Tem a liberdade de ser } \\
\text { feliz, de ter o carro que } \\
\text { quer. } \\
\text { É como um sonho, pode } \\
\text { fazer o que quiser; } \\
\text { Tem a vida assentada, } \\
\text { emprego, cachorro; } \\
\text { O adulto tem tudo. Tudo } \\
\text { lhe é permitido, é forte; } \\
\text { Independente, autônomo; } \\
\text { Sabe o que a vida } \\
\text { significa; sabe onde está, } \\
\text { aonde vai; } \\
\text { Tem vontade de criar } \\
\text { algo; } \\
\text { Não é livre; } \\
\text { Conversa cada vez menos } \\
\text { sobre si; } \\
\text { Tem poucos amigos ou } \\
\text { nenhum. }\end{array}$ & $\begin{array}{l}\text { É perseverante para fazer o } \\
\text { que não deseja, mas deve; } \\
\text { Lado moral é o forte; } \\
\text { Seriedade X “joie de vivre”; } \\
\text { Tem autonomia, é eficaz, é ou } \\
\text { dá o exemplo; } \\
\text { Não pode se permitir perder } \\
\text { tempo; } \\
\text { Passa por questionamentos } \\
\text { constantes, stress, altos e } \\
\text { baixos, depressão, falta de } \\
\text { alegria; } \\
\text { Criança, casa, cachorro } \\
\text { Sua vida é pura monotonia; } \\
\text { Vira-se sozinho; } \\
\text { Tem dificuldade para refazer } \\
\text { vínculos abalados; } \\
\text { Cria outra família, ter filho } \\
\text { torna alguém adulto; } \\
\text { Abandona muitos de seus } \\
\text { projetos; } \\
\text { Desiste de avançar, de amar; } \\
\text { Lado pessimista; }\end{array}$ & $\begin{array}{l}\text { Desenvolve responsabilidade; } \\
\text { Desenvolvimento afetivo; } \\
\text { Alguém que não se encanta } \\
\text { por muita coisa. Sofre perda } \\
\text { de magia; perda de alegria; } \\
\text { Os pais vão para os bastidores; } \\
\text { É exemplo para as crianças; } \\
\text { É alguém insípido, sem graça; } \\
\text { Tem menos aceitação dos } \\
\text { erros. Não pode mais ser } \\
\text { despreocupado; } \\
\text { Menos mulheres são adultas } \\
\text { todo o tempo; } \\
\text { É triste; pesado; } \\
\text { Não pode mais fazer o que } \\
\text { quiser, quando quiser; } \\
\text { Não pode mais se divertir; } \\
\text { Tem menos espontaneidade; } \\
\text { Tem que enfrentar o peso de } \\
\text { ter um filho. }\end{array}$ \\
\hline Temas & $\begin{array}{l}\text { Plenitude (ter), } \\
\text { Sabedoria } \\
\text { Assentamento } \\
\text { Desejo de criar algo } \\
\text { Fechamento } \\
\text { Solidão }\end{array}$ & $\begin{array}{l}\text { Desenvolvimento moral } \\
\text { Dúvida } \\
\text { Pressão social } \\
\text { Desejo de criar família } \\
\text { Perdas/ganhos } \\
\text { Ensimesmamento } \\
\text { Solidão }\end{array}$ & $\begin{array}{ll}\text { Desenvolvimento afetivo } & \mathrm{e} \\
\text { moral } & \\
\text { Tristeza } & \\
\text { Pressão social } & \\
\text { Perdas } & \\
\text { Peso } & \\
\text { Solidão } & \\
\end{array}$ \\
\hline
\end{tabular}

Quadro 2: Resumo das ocorrências de debreagem enunciva.

Vejamos: aos dezesseis anos, os temas tratados sob o efeito de sentido de proximidade são o amor (no casal) e o medo (de ser adulto, do futuro). Em contrapartida, os 
temas em distanciamento são, por um lado, a plenitude, por meio daquilo que o adulto pode ter ou adquirir, e a sabedoria e, por outro, o assentar-se, o fechamento de seu universo e a solidão.

Aos vinte anos, para esse grupo que se considera em transição, os temas em proximidade são conservação vs mudança, perdas, pressão social e medo (do futuro). Desses quatro, dois são desenvolvidos também em distanciamento: perdas vs. ganhos e pressão social. ${ }^{38}$ Vêm juntar-se a esses: o desenvolvimento moral no lugar da plenitude, colocada anteriormente; a dúvida e o ensimesmamento tomando o lugar do fechamento de seu universo; e, novamente, a solidão.

E aos vinte e cinco? Parece desaparecer o medo, mas surge a ideia de contenção. A exemplo do grupo anterior, desenvolvem-se em proximidade: conservação vs. mudança, perdas e pressão social; os dois últimos repetem-se expressos em distanciamento. Igualmente em distanciamento está, ao lado do desenvolvimento moral, o desenvolvimento afetivo. Encontra-se também a tristeza, e surge a ideia de peso opressor no lugar de ensimesmamento. Finalmente, confirma-se a solidão, único tema abordado por todas as entrevistadas, sempre em debreagem enunciva, isto é, como algo objetivo e afastado.

\section{Considerações finais}

Retomando Ricoeur (2004): a identidade é necessariamente narrativa e se formula na tensão dialética entre o eu e o alter e entre o idem e o ipse. O idem constitui-se de características inerentes ao sujeito, enquanto o ipse, componente sócio-histórico, resulta das negociações que o sujeito faz com outrem com quem compartilha o meio em que vive.

O componente sócio-histórico se deixa perceber por meio da figurativização e da tematização. Aquilo que é expresso com efeito de sentido de aproximação e peso de "realidade" é o que o sujeito falante mostra considerar próximo de si e "real". Paralelamente, aquilo que é expresso com efeito de sentido de distanciamento e "objetividade" é o que mostra colocar como distante ou disjunto de si.

A cautela se justifica por o discurso não dar acesso ao ser do sujeito, mas a seu parecer, como dado significante. $\mathrm{O}$ pesquisador tem acesso ao que o discurso faz parecer verdadeiro.

Assim, G1 faz crer ter em comum com o ser adulto os temas do amor no casal e do medo, enquanto considera diferir em o adulto ter atingido a plenitude, decorrente de seu poder aquisitivo, e a sabedoria, mas também por ele se assentar, restringir seu mundo e sofrer de solidão, ou caminhar em sua direção. G2 compartilha com o ser adulto a tensão entre conservação e mudança, conquistas, perdas, pressão social e medo, enquanto se coloca em disjunção com: desenvolvimento moral, dúvida, perdas e ganhos, ensimesmamento e solidão. Finalmente, G3 repete G2 no tangente a dividir com o ser adulto a tensão entre conservação e mudança, as perdas e a pressão social, enquanto não se identifica com desenvolvimento afetivo e moral, tristeza, peso e solidão.

No que se refere à quantidade de ocorrências de cada tipo de debreagem em cada faixa etária, pode-se observar o emprego predominante da debreagem enunciva, estratégia de efeito de sentido de distanciamento, na caracterização do adulto por G1, gradativamente substuída por debreagens enunciativas nas colocações de G2 até a predominância destas, com efeito de sentido de aproximação, nas falas de G3. Na primeira faixa etária, chega-se a uma identidade narrativa do adulto distante e quase edênica, correspondente à de um provedor,

\footnotetext{
${ }^{38} \mathrm{O}$ casamento é posto sob a pressão social, como mostra o dito popular que remete à rotina: enfant, maison, chien.
} 
todo-poderoso, onisciente, mas fechado e só. Tal relação se tensiona e se recaracteriza gradualmente, segundo a idade representada, transportando a adolescência do lugar da "liberdade" para o da "despreocupação" e para o da "cuca fresca" e a idade adulta da "certeza" para a "dúvida", a "tristeza" e o "peso".

Interessa destacar que, enquanto a visão do adulto muda gradativamente, mudam também as estratégias linguístico-discursivas de colocação de pessoas (eu-tu) ou de não pessoas (ele) e de gestão do distanciamento ou da aproximação. Para G1, o adulto é não pessoa (ele) e expresso em distanciamento, exceto pela relação amorosa. Quanto a G2, o adulto oscila, mas predomina como não-pessoa e em distanciamento, a não ser no sofrer perdas e pressão da sociedade. G3, por sua vez, é o grupo que mais vezes o enuncia como pessoa e em proximidade.

Concluindo, nas entrevistas aqui analisadas, a hipótese da dinâmica das representações do adulto, no âmbito da Psicologia, é sustentada pela materialidade linguística e pelos recursos discursivos empregados. De modo complementar, esses recursos linguísticodiscursivos indicam, com o apoio da aspectualização terminativa, uma moralização incidente sobre a dinâmica das representações da adolescência, no tangente às expectativas sociais referentes ao adultecer.

\section{Referências bibliográficas}

AVILA, S. de F. O. de. A adolescência como ideal social. In: Simpósio Internacional do Adolescente 2, Anais, Online, São Paulo, 2005. Disponível em: $<$ http://www.proceedings.scielo.br/scielo.php?script=sci_arttext\&pid=MSC00000000820050 00200008\&lng=en\&nrm=abn>. Acesso em: 17 jan. 2010.

BARROS, Diana Luz Pessoa de. Teoria semiótica do texto. São Paulo: Ática, 2008.

COTE, J. E. \& ALLAHAR, A. Generation on hold: coming of age in the late twentieth century. New York: New York University Press, 1995.

Dictionnaires Français Larousse. Disponível em:

<http://www.larousse.fr/dictionnaires/francais>. Acesso em: 08 ago. 2010.

FIORIN, J. L. Sendas e veredas da semiótica narrativa e discursiva. Delta, vol. 15, n. 1, 1999. Disponível em: <http://www.scielo.br/scielo.php?script=sci_arttext\&pid=S010244501999000100009>. Acesso em: 29 mar. 2010. . As astúcias da enunciação. São Paulo: Ática, 1996.

FRANCO, M. L. P. B. Jovens: uma leitura de suas representações sociais. Difusão de Ideias, São Paulo, Fundação Carlos Chagas, set. 2007, p. 1-12.

GOFFMAN, E. The presentation of self in everyday life. New York: Doubleday / Garden City, 1959.

GREIMAS, A. J. Du sens - essais sémiotiques. Paris: Éditions du Seuil, 1970.

GREIMAS, A. J. \& FONTANILlE, J. Sémiotique des Passions. Paris: Seuil, 1991.

HALL, G. S. Adolescence: Its Psychology and Its Relations to Physiology, Anthropology, Sociology, Sex, Crime, Religion and Education. 2 vols. New York: Appleton, 1904.

HERMANS, H. J. M.; KEMPEN, H. J. G.; LOON, E. J. P. van. The dialogical self: Beyond individualism and rationalism. American Psychologist, 47, 1992, p. 23-33. 
HERMANS, H. J. M. \& KEMPEN, H. J. G. The dialogical self: Meaning as movement. San Diego, Academic Press, 1993.

HERMANS, H. J. M. \& HERMANS-JANSEN, E. Self-narratives: The construction of meaning in psychotherapy. New York, Guilford Press, 1995.

IMANISHI, H. A. A imagem do adulto na contemporaneidade: uma avaliação dos jovens sobre os adultos. 2009. (Dissertação de Mestrado apresentada ao Instituto de Psicologia da Universidade de são Paulo). Disponível em:

$<$ http://www.teses.usp.br/teses/disponiveis/47/47131/tde-21012009-103811/>. Acesso em: 10 ago. 2010.

KAUFMANN, J.-C. L’entretien compréhensif. Paris: Ed. Nathan, 1996.

LANDOWSKI, E. Les interactions risquées. Nouveaux Actes Sémiotiques, Limoges, Pulim, 2006, 108 p.

MAINGUENEAU, D. Approche de l'énonciation em linguistique française. Paris: Hachette, 1981.

Mc ADAMS, D. P. The case for unity in the (post)modern self: A modest proposal. In: ASHMORE, R. \& JUSSIM, L. (Eds.). Self and identity: Fundamental issues. New York: Oxford University Press, 1997, p. 46-78. p. $100-122$.

The Psychology of Life Stories. Review of General Psychology. vol. 5, n. 2, 2001,

PIMENTA, M. de M. Ser jovem e ser adulto: identidades, representações e trajetórias. 2008. (Tese de Doutoramento apresentada na Faculdade de Filosofia, Letras e Ciências Humanas da USP). Disponível em: <http://www.teses.usp.br/teses/disponiveis/8/8132/tde-15052007111215/pt-br.php>. Acesso em: 24 dez. 2010.

RICOEUR, P. Temps et récit. Tome II: La configuration dans le récit de fiction. Paris: Seuil, 1994.

Parcours de la reconnaissance: trois études. Paris: Stock, 2004.

ROBINSON, J. A. \& TAYLOR, L. R. Autobiographical memories and self-narratives: A tale of two stories. In: C. P. Thompson et al. (Eds.). Autobiographical memory: Theoretical and applied perspectives. London: Lawrence Erlbaum Associates, 1998, p. 125-143.

SANTOS, M. F. de S.; ALÉSSIO, R. L. dos S.; ALBUQUERQUE, C. M. da C. Adultos e jovens: diferentes olhares sobre o desenvolvimento. Revista de Educação Pública, Cuiabá (MT), v. 16, n. 30, jan./abr. 2007, p. 105-120.

SENNET, R. Les tyrannies de l'intimité. Paris: Seuil, 1979.

SOUSA, F. C. O que é ser adulto? As velhas e novas representações sociais sobre o que é ser adulto, 2004. Disponível em:

$<$ http://www.aps.pt/Index.php?area=001\&marea=003\&id_pub=PUB460d42061fd7a $>$. Acesso em: 24 dez. 2010.

. O que é "ser adulto": as práticas e representações sociais sobre o que é "ser adulto" na sociedade portuguesa. Revista Moçambras: Acolhendo a alfabetização nos países de língua portuguesa, São Paulo, vol. 1, n. 2, 2007, p. 56-69. Disponível em:

<http://redalyc.uaemex.mx/pdf/879/87910206.pdf>. Acesso em 15 ago. 2010. 
CASA, Vol.9 n.1, julho de 2011

ZILBERBERG, C. Pour saluer l'événement. Nouveaux Actes Sémiotiques, 2006. Disponível em: 〈http://revues.unilim.fr/nas/document.php?id=2485〉. Acesso em: 17 ago. 2010.

Recebido em: 26.12 .10

Aprovado em: 26.04.11 